\title{
Review \\ What Have We Learned in 30 Years of Investigations on Bari Transposons?
}

\author{
Antonio Palazzo (D), Ruggiero Caizzi, Roberta Moschetti and René Massimiliano Marsano * \\ Dipartimento di Biologia, Università di Bari, 70125 Bari, Italy; antonio.palazzo@uniba.it (A.P.); \\ ruggiero.caizzi@gmail.com (R.C.); roberta.moschetti@uniba.it (R.M.) \\ * Correspondence: renemassimiliano.marsano@uniba.it
}

check for updates

Citation: Palazzo, A.; Caizzi, R.; Moschetti, R.; Marsano, R.M. What Have We Learned in 30 Years of Investigations on Bari Transposons?. Cells 2022, 11, 583. https:// doi.org/10.3390/cells11030583

Academic Editors: Laura Fanti and Patrizio Dimitr

Received: 12 January 2022

Accepted: 7 February 2022

Published: 8 February 2022

Publisher's Note: MDPI stays neutral with regard to jurisdictional claims in published maps and institutional affiliations.

Copyright: (C) 2022 by the authors. Licensee MDPI, Basel, Switzerland. This article is an open access article distributed under the terms and conditions of the Creative Commons Attribution (CC BY) license (https:// creativecommons.org/licenses/by/ $4.0 /)$.

\begin{abstract}
Transposable elements (TEs) have been historically depicted as detrimental genetic entities that selfishly aim at perpetuating themselves, invading genomes, and destroying genes. Scientists often co-opt "special" TEs to develop new and powerful genetic tools, that will hopefully aid in changing the future of the human being. However, many TEs are gentle, rarely unleash themselves to harm the genome, and bashfully contribute to generating diversity and novelty in the genomes they have colonized, yet they offer the opportunity to develop new molecular tools. In this review we summarize 30 years of research focused on the Bari transposons. Bari is a "normal" transposon family that has colonized the genomes of several Drosophila species and introduced genomic novelties in the melanogaster species. We discuss how these results have contributed to advance the field of TE research and what future studies can still add to the current knowledge.
\end{abstract}

Keywords: Bari transposons; Drosophila; regulation; transposon tandem repeat; horizontal transfer; blurry promoter; heterochromatin

\section{Introduction}

Transposable elements are fundamental genetic units in the genomes of virtually all living organisms. TEs could be depicted as the characters of a happy ending fairytale. Initially regarded as "junk" and "useless", TEs turned out to be considered as evolutionarily flagships after reconsidering the role they have had and still have in shaping genomes and their functioning. Moreover, the characterization of many transposition systems has led to the development of efficient DNA integration tools [1] as well as powerful genome engineering systems [2,3], and to the implementation of TE control regions into efficient expression systems [4].

It is a matter of fact that the hallmark of all TEs, i.e., the ability to integrate into chromosomes, is the most interesting aspect of TEs for many biologists, due to their many possible applications in a large group of fields in Life Sciences.

Efficient genome integration tools are indeed desirable to disrupt genes, either in a random or targeted way, and to introduce exogenous DNA into the preferred cellular or animal model. A special application of the latter practice is gene therapy, which consists in the introduction of the non-pathological allele in the affected cell type of a patient that suffers from a genetic-based disease, with the aim to rescue the illness phenotype.

In the past 40 years many transposition systems have been studied in detail with the aim to set up new and efficient DNA integration tools.

Historically, the Drosophila P-element was the first transposon-based transposition tool to be employed in functional genomics [5,6]. Unfortunately, its main limitation is the narrow host range of transposition [7], which makes it useless for much noble applications, such as gene therapy.

Elements of the Tc1/mariner are more tractable for this kind of application. Tc1/mariner elements belong to the Class II of the eukaryotic transposons and are widely distributed, 
from bacteria [8] to higher eukaryotes [9], with few exceptions. Their wide distribution in living organisms allowed the foundation of the IS630/Tc1/mariner superfamily.

More in general, the so-called "cut and paste" DNA transposons are the best candidates to develop molecular tools for transgenesis because of their simple mechanism of transposition and their poor requirement of host factor [10]. Two of these elements stepped into the limelight in the past decade, the Sleeping Beauty (SB) and the piggyBac (PB) elements [1]. SB is undoubtedly the most sophisticated transposon-based system in the context of therapeutic setup. The CARAMBA clinical trial (https:/ / www.caramba-cart.eu; accessed 15 December 2021) currently uses an advanced SB-based transposon technology for therapeutic gene delivery [11].

However, not all the known transposition systems support this kind of application. Most known TEs have limited transposition performances (i.e., low transposition rate, narrow host specificity) or they have low flexibility (i.e., they are too large and complex or display low cargo capability) to allow the development of efficient genome integration systems. Nevertheless, many TEs are studied for their role in shaping genome structure [12] and gene expression [13] or to develop new and alternative technologies $[3,4,14,15]$.

Among the Tc1/mariner superfamily of TEs the Bari family was discovered 30 years ago in the former Institute of Genetics at the University of Bari (Italy). Such discovery led to the foundation of a new research line, which is still currently under investigation, in a laboratory up to that time devoted to the study of glutamine synthetase [16-18].

In this review, we comprehensively summarize the results of 30 years of research that concern the Drosophila Bari elements, and frame these results in a comprehensive view in the field of TE research. We also provide more extensive hypotheses on the role of Bari transposons in the genome of Drosophilidae species.

\section{The Discovery of the Bari1 Transposon: An Historical Overview}

The discovery of the Bari transposons occurred during the characterization of the h39 region of the mitotic chromosomes. This is a complex repetitive locus in Drosophila melanogaster, adjacent to the second chromosome's centromere [19]. It was known from previous studies that mutant flies carrying the deletion of the $\mathrm{h} 39$ region showed a semi-lethal phenotype and low fitness [20]. The phenotype was associated with the deletion of the Responder satellite [21], the main satellite mapped in the h39 until then.

The team headed by Prof. Caizzi and Prof. Pimpinelli hypothesized that additional genetic and molecular entities could map in the $\mathrm{h} 39$ region, which could also account for the phenotype associated with the region deletion. In the main effort of characterizing the h39 region at the molecular level, they identified a novel repetitive sequence, uniquely mapping to this region. Originally, differential hybridization technique was used to identify, isolate, and subsequently clone h39-specific sequences. The existence of extraordinary genetic toolkits, such as precisely mapped chromosome rearrangements (the most effective was the Rsp ${ }^{\text {ins16 }}$ (R16) deletion [22,23]) undoubtedly aided the genetic mapping in a heterochromatic region. Furthermore, the availability of molecular tools, such as the possibility to construct strain-specific genomic libraries, but most of all acrylamide gel electrophoresis to read Sanger sequencing reactions, strongly contributed to the characterization of a previously unknown sequence isolated from single copies dispersed in the euchromatin that was soon classified as a new transposon of the Tc1/mariner superfamily. It was named Bari1 after its discovery in the Italian city of Bari, where the laboratory was based, and making the wish (which would later come true!) that other Bari elements might be discovered to complete the series.

Bari1 is a DNA transposon belonging to the IS639/Tc1/mariner superfamily with $26 \mathrm{bp}$ long inverted repeats (IRs) and three direct repeated sequences (DRs) [24], serving as the transposase binding sites (Figure 1A). As noted earlier in comparative studies, the 3xDRs structure is almost peculiar [25], since there are few known TEs with similar organization of the terminal sequences, including Paris [26], S [27], minos [28], and SB [29]. 
If the identification of a new transposon in the early 1990s was per se a great advancement in the field of genome structure and evolution, the characterization of the peculiar arrangement of Bari1 in a heterochromatic locus was breathtaking. The precise head-to-tail organization of roughly 80 Bari1 copies in the h39 region of the mitotic chromosomes of D. melanogaster was featured by the systematic deletion of the very first two nucleotides in each copy. To our knowledge, this enigmatic organization still has no comparable described examples in the field of TEs. While other Drosophila species contain Bari-like transposons (see the Section "The Bari Family Grows Up"), the heterochromatic Bari1 cluster seems to be specific to the melanogaster species. This organization suggests a recent-and species-specific evolutionary origin since it is specific to a single species. It also allows the discrimination of two sibling species (i.e., the melanogaster and simulans species) at the molecular level. Moreover, a second minor Baril cluster has been recently described, which maps on the $\mathrm{X}$ chromosome of $D$. melanogaster $[30,31]$. This is a small cluster that is composed of six copies of Bari1. Surprisingly, both the main and the small clusters share the same di-nucleotide deletion at the $5^{\prime}$ end of each element, and the head-to-tail organization. In addition, both clusters share a heterochromatic localization, although on different chromosomes. In a retrospective view, it is worth noting that the presence of an additional Bari1 tandem repeat was also evident since the 1993 paper. Indeed, in one of the Southern blot hybridization analyses presented in the paper, it was evident that the Rsp ${ }^{\text {ins16 }}$ background still contains an additional Bari1 sequence block arranged in a tandem repeat configuration (see Figure 4 in Caizzi et al., 1993 [32]. A similar pattern can be observed in Caggese et al., 1995 [33] (see Figure 2 therein), an observation that allows excluding technical artifacts. Taken together, these findings suggest a marked instability of the Baril element in the melanogaster species, associated with an error-prone transposition that has occurred at least twice during the evolution [34]. An aberrant transposase activity that generated long concatemers form a circular transposon, in a way similar to the rolling circle replication mechanism, has been proposed to explain the origin of both the Bari1 arrays [34]. However, the structural and functional role of these clusters (if any) remains currently unresolved.

Among the possible role of the Bari clusters, two scenarios can be envisioned. The simplest hypothesis is that it could have a regulatory function. The second hypothesis, which we are currently testing using transgenic strains, is that the Bari cluster could be involved in the structural organization of h39 domains, possibly aided by other repetitive sequences mapping in the same region [35-37]. 
A

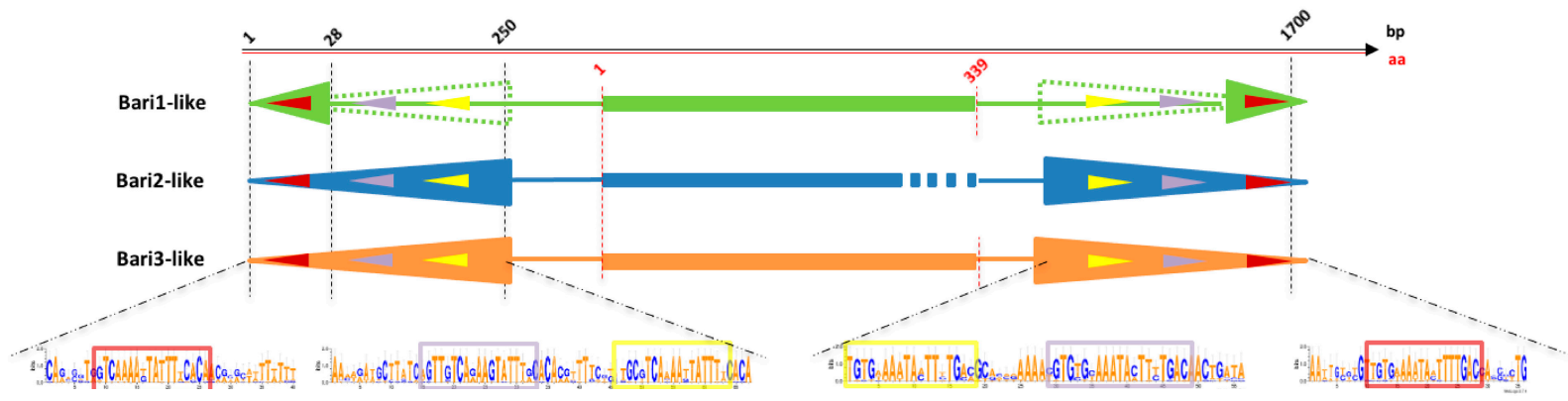

B
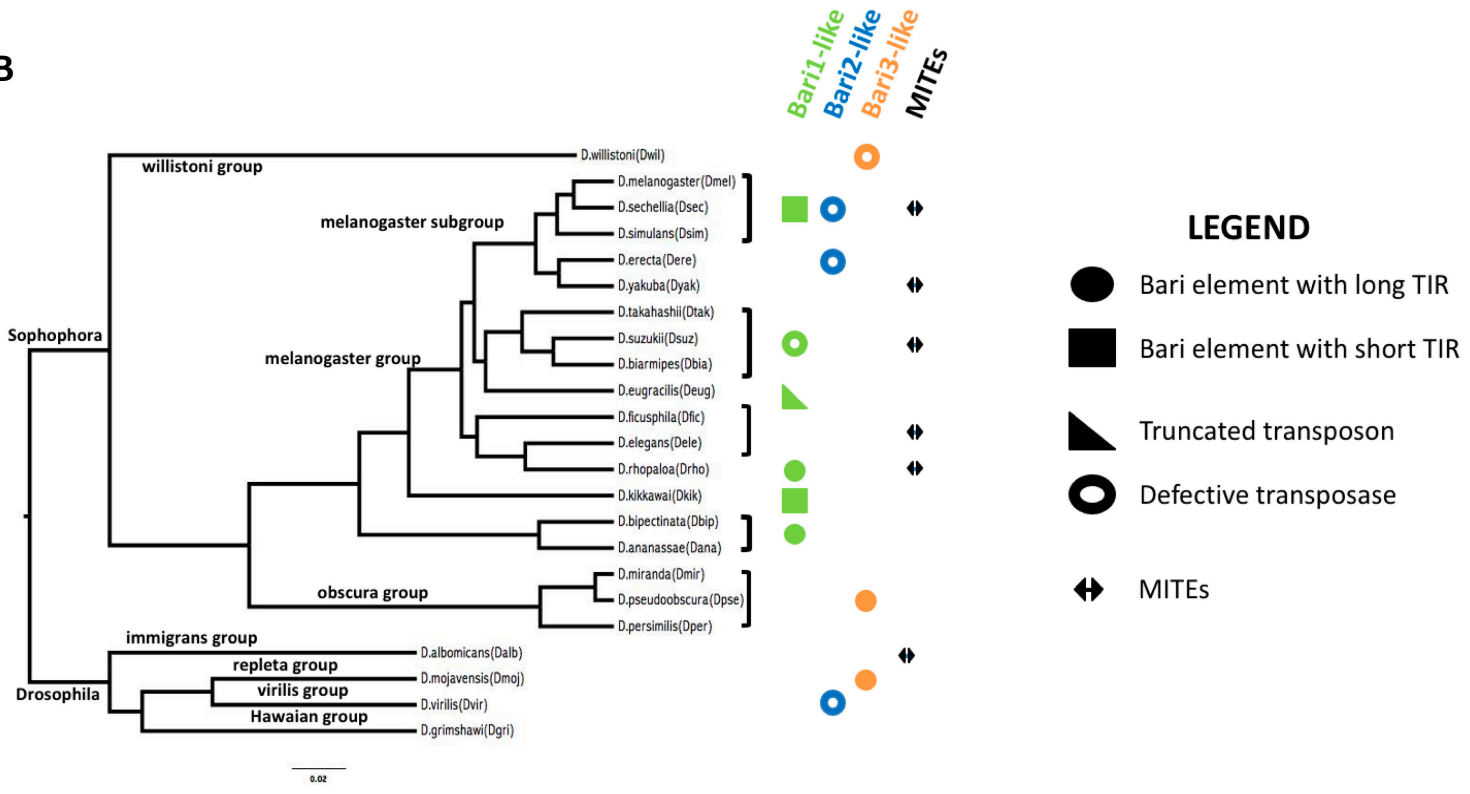

Figure 1. (A) Structure and TIRs organization of the three Bari sub-families. The length of the TIRs is indicated by colored arrowheads. Baril elements may have two different TIR lengths (represented by solid and dashed green arrowheads, respectively). The three DRs (outer (red), middle (violet), and inner (yellow)) are shown as DNA logos [38] obtained by comparing at least 15 different Drosophila species. The elements represented in the picture (TIRs, ORFs) are not drawn to scale. (B) Distribution of Bari-like elements in the Drosophilidae (adapted from [30]). Symbols are explained in the figure legend and have the same color-code as in panel A (i.e., Bari1-like green; Bari2-like blue; Bari3like orange).

\section{The Bari Family Grows Up}

\subsection{Introducing Bari2 and Bari3}

Studies aimed at the determination of the diffusion of the Bari transposons in Drosophila genus and in other Diptera species demonstrated that Bari transposons are widely represented in the Drosophila genus and that they can be subdivided into three distinct sub-families.

Former studies, mainly performed using Southern blot hybridization techniques, demonstrated the presence of homologous Bari1 sequences in species closely related to D. melanogaster [39]. Weak or very faint hybridization signals suggested the presence of Bari elements that were divergent in sequence in distant species, belonging to the Sophophora and Drosophila sub-genera, and to the Zaprionus genus. Indeed, cloning and sequencing hybridizing fragments (showing weak hybridization signals) from $D$. erecta and D. diplacantha demonstrated the presence of another type of Bari element, which was named Bari2, in the genome of many species in which the Bari1 element was also found. Bari2 differs from Bari1 in structure, since it is characterized by long TIRs (nearly identical $253 \mathrm{bp}$ sequences) and no coding potential, due to numerous invalidating indels and frameshift mutations that disrupt its ability to encode a transposase (Figure 1A). Not a single active 
Bari2 element has been found to date, making Bari2 a non-autonomous sub-family. Notably, the distribution of Bari2 in the genome of D. erecta is almost heterochromatic, suggesting either an insertion preference of the ancestral (active) form of Bari2 or a recent elimination of the euchromatic copies.

The evolutionary link between the potentially active Bari1 and the evolutionary knocked out Bari2 elements was also difficult to understand. While the comparison of the ORF (and its protein product) of Bari1 and the reconstructed consensus sequence of Bari2 clearly suggested their evolutionary relationship, their TIRs are very dissimilar both in sequence and structure. Bari2 is indeed featured by long TIRs, identical to each other. Only at the DRs level the two families share evident homology, a sign that both derived from an ancestral Bari transposon [24]. Why the TIRs of Bari2 have been preserved in extant Drosophila species is not clear. An intriguing hypothesis, that parallelizes the one proposed for the human Hsmar1 element, is that Bari2 TIRs have been co-opted to titrate some endogenous nuclear protein $[40,41]$ involved in the maintenance of the chromatin status or in chromatin remodeling or to titrate the transposase of active Bari elements.

The missing evolutionary link between Bari1, possessing short TIRs and intact ORF, and Bari2, possessing long TIRs and disrupted ORF, was subsequently identified with the discovery of the third Bari family in D. mojavensis [24]. Bari3 was next identified in species of the obscura and the willistoni groups [30]. Many intact Bari3 insertions and the polymorphism observed in geographically distinct populations suggested that it is an active transposon [42]. Bari3 transposases share $80 \%$ similarity with Bari1, and it is featured by long TIRs with an IR/DR structure (Figure 1A) [24,42].

\subsection{New Cognate Elements in New Species: The Crew Grows up in the Post-Genomic Era}

The advent of the post-genomic era has offered the opportunity to perform comparative studies that were very difficult to perform without the availability of genome sequence assembly. Evidence of the presence of Bari elements in distant Drosophila species were mounting in a former work which identified homologous sequences in the Sophophora and Drosophila genera [39]. In a genomic survey study conducted in 23 species of Drosophila, several other elements related to the three known Bari sub-families were identified in newly sequenced Drosophila genomes (Figure 1B) [30]. In this study, Bari-like elements were identified and annotated in all but the D. grimshawi species. The extended annotation of Bari-like transposons suggests that, despite the diversity observed in the TIR structure, the DRs are well-conserved across Bari sub-families (Figure 1A) [24,30]. It is worth noting that an interesting Bari1-type element with long TIRs was identified in D. rhopaloa (Figure 1B), which further entangles the evolutionary dynamics involving the terminal ends of the Bari transposons.

The evolutionary scenario observed in the extant Drosophila species is complicated by the presence of an additional group of non-autonomous sequences called MITEs (Figure 1B). MITEs (Miniature Inverted repeats Transposable Elements) are frequently found in eukaryotic genomes [43-46] and they are considered as evolutionary byproducts, originating from a rearranged (i.e., internally deleted) ancestral form of TIR elements. Their subsequent amplification in the genome occurred through trans-complementation with the functional transposase expressed by active TEs. Bari-derived MITEs have been identified in D. sechellia [47] and in other Drosophila species [30]. Bari-derived MITEs can be categorized either as short- or long-MITEs, depending on their sequence length. While both forms share the same terminal sequences, the internal sequence can be highly variable in length, with the long form exhibiting sequences unrelated to Bari transposons [30]. It has been proposed that the TIRs of both functional and defective copies (including MITEs) that retain the transposase binding activity can act as buffer to titrate endogenous levels of the transposase, [40]. Therefore, it is possible that also Bari-derived MITEs are maintained for this regulatory purpose. 


\section{Horizontal Transfer Events Involving Bari Elements}

Horizontal transfer (HT) is one of the most obscure yet fascinating aspects underlying the evolutionary dynamics of the genomes $[48,49]$. TEs are among the most prone DNA sequenced to take part in HT events [50,51]. While during the pre-genomic era horizontal transposon transfer (HTT) events could be only detected using molecular assays, currently we have potent bioinformatic tools that allow HTT inference supported by statistical methods [52]. It is now more evident from genome sequence comparison that HTT commonly occurs during evolution but it is hard to detect only for two basic limitations in our approaches. The first is intrinsic to the HTT process, in that we could detect it if occurs in germline cells. In this case, the horizontally transferred DNA can be transmitted in the population and we can detect it as an "alien" piece of DNA. Somatic HTT events could conversely result in a small number of mosaic organisms and would not be detected because of the low (or very low) representation of the transferred sequence in whole genome extracts. The second limitation in detecting HTT is due to the restricted number of sequenced genomes, compared to the number of extant species. Furthermore, even if there are more than 20,000 genome projects in NCBI (different advancement statuslast access early December 2021) they refer to small individual samples, representative of entire populations or species. This gives us a poor vision of the sequence variability caused by HTT, with a consistent loss of event detection at the population level.

Several studies suggest that Baril moved horizontally several times during the evolution among Drosophilidae species. Several works provide evidence that Bari1 HT occurred between D. melanogaster and D. simulans [53], between D. melanogaster and D. yakuba [54], and between D. melanogaster and D. sechellia [52]. Moreover, an additional study in 23 sequenced species of Drosophila showed that horizontal transfer involving Baril elements also occurred between D. biarmipes and D bipectinata [30]. Bari1 elements in the two species are nearly identical in sequence, despite that the host species divergence dates back to 27 million years ago [55].

\section{The Missing Jump to the Next Level}

\subsection{Why We Cannot Use Bari Transposons as Tools for Chromosomal Integration}

An initial effort to develop a new chromosomal integration tool based on the Bari1 transposon was made in Drosophila [56]. A binary transposition system was constructed along the same lines of the P-element system: a helper plasmid (the transposase source) and a donor plasmid (the transposon source marked with a white reporter gene), were injected into genotypically suitable fly embryos with the goal of genetically transforming the recipient strain. After the initial excitement due to the identification of few transposition events (i.e., red-eyed individuals), their molecular characterization turned out to be puzzling and frustrating, since the observed phenotype was due to transposition of the NOF-FB transposon rather than the transposition of Baril from the donor plasmid. To make a long story short, the expression of the Bari1 transposase from the helper plasmid has possibly deregulated the NOF-FB transposon [56], whose transposition is not currently known and may depend on the activity of unrelated active transposases. Taken together, these fortuitous observations remind us that unpredictable and complex interactions occur when we attempt to manipulate the genome. Following a stress condition, the genome reacts, and the fastest response is often given by the de-repression of transposable elements in several species [57-60]. We are currently investigating the possible cross-interaction between the overexpression of the Bari1 transposase and the transposition of NOF-FB in vivo.

Similar attempts to observe the transposition of Bari elements through a transposition assay were made using cultured cells as experimental systems. Setting up a binary system, in which the donor transposon was marked with a reporter cassette and the transposase was expressed by a helper plasmid, did not result in a significant integration over the background in Drosophila and human cultured cells [42,61]. Finally, even correcting the diverging aminoacidic residues in critical transposase subdomains, with the guide of a 
multiple transposase alignment containing other active Tc1-like transposons, does not significantly improve the transposition efficiency of Bari1 in heterologous transposition assays (RMM unpublished observations).

\subsection{Active or Non-Active? That Is the Question}

The reiterated and unsuccessful attempts to develop an efficient transposition system from Bari elements led to question whether Bari transposons are transposition-competent. Excluding the Bari2 sub-family, which is entirely composed of non-autonomous elements [39], members of the Bari1 and Bari3 sub-families have what it takes to be regarded as functional.

Standing to the general architecture of the IS630/Tc1/mariner transposase, the fundamental domains of this enzyme are the DNA binding domain, the GRPR-like domain (which mediates protein-protein interactions), the nuclear localization signal, the homeolike domain, and the catalytic domain [25]. All these domains can be predicted in the transposase of both Bari1 and Bari3. Furthermore, the functionality of the DNA binding domain has been tested in vitro for both transposons [42,61]. In addition, there is indirect evidence of the transposition ability of Bari transposons coming from population genetics studies.

A series of population genetics analyses strongly suggest that Bari1 is an active transposon in natural populations of D. melanogaster. Early studies were performed in 46 populations of D. melanogaster, which suggested both Bari1 inter- and intra-stock polymorphisms [33]. Junakovic and collaborators performed additional studies on a Charolles laboratory population using Southern blot hybridization of single-fly genomic digestions. A strong difference in the insertion pattern can be highlighted in unstable (Charolles) versus stable laboratory strains, suggesting that host factors control the transposition frequency [62] and the insertion preference [63] of Bari1. The strongest evidence that Bari1 is a functional transposon comes from the observation of an excision event in a population established from field-collected flies. The excision event, involving one of the two adaptive Bari1 insertions in the genome of D. melanogaster, was characterized at the molecular level, demonstrating that it was due to genuine transposition (i.e., presence of the transposition footprint) [64].

In conclusion, combining the indirect genetic evidence of the mobility of Bari1 transposon with the outcome of the experimental transposition assays, we argue that Baril could be tightly regulated, or alternatively we speculate that Bari1 could be subjected to some unknown types of activation to become transposition-competent. Further and extensive in vitro-directed molecular evolution studies would clarify whether hyperactive variants can be obtained to develop Bari-based transposition systems.

\section{What Do We Know about the Regulation Bari Transposons?}

The transposition activity of TEs is tightly regulated at various levels. The copy number per haploid genome is a critical factor for the resulting fitness of the whole organism since an excessive TE load can be deleterious for various reasons, ranging from the gene inactivation to the disturbance of the physiological expression networks [13].

Standing to the current knowledge on Tc1/mariner elements, two possible types of regulation can be predicted. One is the transposon self-regulation while the other one is the epigenetic regulation.

One mode of self-regulation is exerted through the dissemination throughout the genome of inactive TE copies that still retain the transposase binding ability. Defective copies can act as buffer to titrate endogenous levels of the transposase [40]. Since defective copies of Bari elements are abundant, it is conceivable to hypothesize this mode of autoregulation.

There is some experimental evidence in favor of the self-regulation of Bari elements through post-transcriptional processing of the transposase mRNA. Few reported data come from overexpression of the transposase in $\mathrm{S}_{2} \mathrm{R}^{+}$cultured cells and in D. melanogaster embryos [42,61] (Figure 2A). Under these experimental conditions, Bari1 and Bari3 transcripts 
undergo alternative splicing that is potentially translated into a truncated transposase protein. It can be predicted that the transcriptional de-repression of Bari elements can inhibit the transposition through the expression of a dominant-negative transposase form. The presence of alternatively spliced transcripts of Bari1 has also been reported in a D. melanogaster HSP83 mutant that deregulates many transposons, including Bari1 $[65,66]$. Possibly, the construction of synthetic Bari1 and Bari3 transposase genes in which all the conventional, unconventional and cryptic splicing sites have been eliminated, could hopefully enhance the transposition efficiency of both systems.

\section{Bari Transposons Regulation Relies on the piRNA Pathways}

The second mode of regulation of TEs is at the chromatin level. The transcriptional control of TEs is intimately connected to chromatin control at the TE insertion site, and this is possible through the recruitment of specific chromatin remodeling complexes that either open or close the chromatin, thus influencing the transcription.

Genomic structural and transcriptional changes are at the basis of stress responses. In this view, TEs are an amazing source of variability in the short temporal timeframe that allows organisms to promptly react to virtually any kind of stress [67].

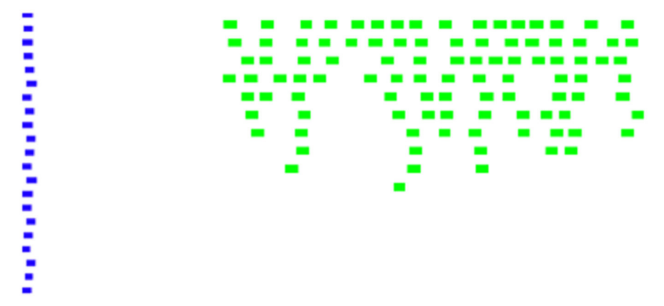

Figure 2. The regulation of Bari transposons. (A) Spliced transposase mRNA of Bari1 (green) identified in [61] and Bari3 (red) identified in [42]. Both spliced transcripts encode a transposase with non-functional catalytic domain. (B) Distribution of piRNA mapping to the Bari1 transposon. The amount of piRNA is purely representative of the relative fraction matching the ORF (green) or the heterochromatic inter-monomer junctions (blue) of Bari1 (see text for further details). A reference element.

Piwi-interacting RNAs (piRNAs) are the most abundant non-coding RNAs in the germline, aiming at the genome safeguard against TE movement [68]. Their action is mainly exerted through the transcriptional silencing. piRNAs usually originate from the so-called piRNA clusters, genomic loci riddled of TE relics that form long non-coding RNAs that are further processed into piRNAs that selectively degrade TE transcripts [69]. Subsequently, a heterochromatic repressive state can be induced at the TE insertion site, reinforcing the transposition control [70-72].

In several published reports, piRNA sequences matching Bari1 and Bari2 are described [73,74], confirming that Bari transposons are among the plethora of Drosophila TEs that are regulated by the piRNA pathway in the germline (Figure 2B). In addition, impairment of the piRNA pathway leads to the transcriptional activation of Bari1, such as in the HSP83 mutant [65], suggesting that transcriptional activation occurs upon piRNA depletion.

Despite the lack of experimental evidence, both Bari clusters of D. melanogaster might support the transcriptional repression of the Bari elements. The clusters might indeed act as 
piRNA clusters, through the expression of small RNA molecules (i.e., piRNA and siRNA) that in turn regulate the transposition frequency.

Several databases offer the opportunity to search in silico annotated Drosophila piRNAs, using sequence similarity criteria. In the piRBase database [75], more than $5800 \mathrm{piR}-$ NAs can be retrieved using Bari1 as a query. Roughly 3800 of them recognize the Bari1 transposase gene. Notably, a small proportion of piRNAs matching the sequence across the monomer-to-monomer junctions-typical of the Bari1 heterochromatic clusters-can also be found (Table 1 and Figure 2B). Why a piRNA should be directed against a piece of untranscribed DNA is, however, unclear. Are they byproducts of the piRNA loci transcript maturation or could they have some regulatory or structural role? Time (and further investigations) will tell.

However, direct genetics evidence is currently lacking in support of the piRNA cluster role of the Bari1 arrays. The currently available chromosomal heterochromatic deletion that removes the Baril cluster in the h39 region also deletes the adjacent Responder locus ([32] and references therein; [76]), while deletion only involving one of the main satellites would be more useful. In addition, the lack of precise mapping of the small X-linked cluster currently makes it impossible to perform detailed genetic studies in a Bari-cluster null genetic background. Hopefully, such kind of chromosomal aberrations will be soon available due to the application of the most modern genome editing techniques. 
Table 1. piRNAs targeting the Bari1 inter-monomer junction. Data extracted from the piRBase database [75] (last accessed March 2021). The sequence used to query the database encompasses an inter-monomer junction of the heterochromatic Bari1 cluster (TTTGACCACCTCTGGTCATGGTCAAAATTAT). Sequence matching either the left or the right monomers are marked with different colors (blue and red, respectively). $\mathrm{O}=$ ovaries; $\mathrm{F}=$ follicle cells; $\mathrm{E}=$ eggs; $\mathrm{W}=\mathrm{wild}$ type $\mathrm{T}=$ transgenic; $\mathrm{M}=$ mutant

\begin{tabular}{|c|c|c|c|c|c|c|c|}
\hline Name & Tissue & $\begin{array}{c}\text { Genetic } \\
\text { Background }\end{array}$ & Methods & Reads & Sequence & Length & Reference \\
\hline piR-dme-2858217 & $\mathrm{O} ; \mathrm{E}$ & $\mathrm{W} ; \mathrm{T} ; \mathrm{M}$ & $\begin{array}{c}\text { oxidized small RNA } \\
\text { small RNA } \\
\text { small RNA }\end{array}$ & $1-3$ & TTTGACCACCTCTGGTCATGGTCAAAA & 27 & [77-79] \\
\hline piR-dme-3826713 & $\mathrm{O}$ & $\mathrm{W} ; \mathrm{T} ; \mathrm{M}$ & oxidized small RNA & $1-6$ & TCTGGTCATGGTCAAAATTATTTT & 24 & {$[77,79-81]$} \\
\hline piR-dme-8496440 & $\mathrm{O}$ & $\mathrm{T}$ & small RNA & $1-3$ & TTTGACCACCTCTGGTCATGGTCAA & 25 & [80] \\
\hline piR-dme-21388569 & $\mathrm{F} ; \mathrm{O}$ & $\mathrm{W} ; \mathrm{T}$ & small RNA & $1-9$ & TTTGACCACCTCTGGTCATGGTCAAAAT & 28 & {$[79,81,82]$} \\
\hline piR-dme-21631816 & $\mathrm{O}$ & $\mathrm{W}$ & small RNA & 1 & CACCTCTGGTCATGGTCAAAATTAT & 25 & {$[83]$} \\
\hline piR-dme-26496558 & $\mathrm{O}$ & $\mathrm{T}$ & small RNA & 1 & ACCACCTCTGGTCATGGTCAAAATTA & 26 & [79] \\
\hline piR-dme-26779428 & $\mathrm{O}$ & $\mathrm{T}$ & small RNA & 1 & CCACCTCTGGTCATGGTCAAAAT & 23 & [79] \\
\hline piR-dme-27814712 & $\mathrm{O}$ & $\mathrm{T}$ & small RNA & 1 & TCTGGTCATGGTCAAAATTATTT & 23 & [79] \\
\hline piR-dme-29438648 & $\mathrm{O}$ & $\mathrm{T}$ & small RNA & 1 & TGACCACCTCTGGTCATGGTCAAA & 24 & [79] \\
\hline piR-dme-29670403 & $\mathrm{O}$ & $\mathrm{T}$ & small RNA & 1 & TTGACCACCTCTGGTCATGGTCAAAA & 26 & [79] \\
\hline piR-dme-30537191 & $\mathrm{O}$ & $\mathrm{T}$ & small RNA & 2 & TTTGACCACCTCTGGTCATGGTCAAA & 26 & [79] \\
\hline piR-dme-31705044 & $\mathrm{O}$ & $\mathrm{T}$ & small RNA & 1 & CTCTGGTCATGGTCAAAATTATTT & 24 & [79] \\
\hline piR-dme-33774286 & $\mathrm{O}$ & $\mathrm{W}$ & small RNA & 1 & TGACCACCTCTGGTCATGGTCAAAAT & 26 & [81] \\
\hline piR-dme-38817646 & $\mathrm{O}$ & $\mathrm{T}$ & small RNA & 1 & CTCTGGTCATGGTCAAAATTATTTT & 25 & [81] \\
\hline
\end{tabular}




\section{Do Bari Transposons Have a Role in The Genome?}

\subsection{Contribution in Creating Somatic Mosaicism and Adaptive Insertions}

It has been reported that TEs are unleashed in some circumstances, to create somatic variability that could have a physiological relevance in certain tissue types [84]. The somatic instability of several TEs has been described in two recent papers. The first paper described the genetic mosaicism of the neurons in the mushroom bodies [85], although this phenomenon has been resized after further studies $[86,87]$. The second study revealed the somatic transposition in the intestinal stem cells $[88,89]$. In both cases, Bari1 was found among the mobilized TEs responsible for the somatic mosaicism in the two tissue types.

The early distribution studies [33] suggested a patchy distribution of Bari1 euchromatic insertions among 46 different populations of D. melanogaster collected worldwide. By contrast, at least two insertions were invariably detected in all the populations analyzed. These insertions occurred at the $55 \mathrm{~F}$ and $91 \mathrm{~F}$ bands of the polytene chromosomes. After the completion of the Drosophila genome-sequencing project [90], it appeared clear that both insertions were intimately connected to host genes. Indeed, the insertion in the $55 \mathrm{~F}$ region falls near the Juvenile hormone epoxy hydrolase (Jheh) gene cluster (Bari-Jheh insertion), while the 91F insertions are associated to the cyp12a4 gene (Bari1-Cyp12a4 insertion). Further studies in which ChIP-seq data were integrated with gene expression analyses and phenotypic assays demonstrated that the Bari-Jheh insertion introduced extra antioxidant response elements upstream of Jheh1 and Jheh2 genes [91]. Furthermore, BariJheh is differentially associated to H3K27me3 in stress vs. non-stress oxidative conditions, suggesting the addition of histone marks to the intergenic region between Jheh 2 and Jheh 3 genes, and its association with histone marks enrichment in the promoter of Jheh1 gene [92].

The Bari1-Cyp12a4 insertion overlaps with the $3^{\prime}$ end of the Cyp12a4 gene and it contributes to the stability of the mature transcript. It has been demonstrated that Bari1Cyp12a4 supplies the polyadenylation sequence to the Cyp12a4 transcript [64].

In addition, the Bari1-Cyp12a4 showed an enrichment of H3K27me3 under oxidative stress conditions [92], suggesting an active role of the insertion in altering the epigenetic context in response to stress.

\subsection{Possible Role in Chromatin Assembly}

TEs can also act as potent epigenetic modifiers that could change both gene expression and chromatin structure [93] with important evolutionary implications [94]. This is possible thanks to the ability to recruit chromatin proteins [95].

Large-scale mapping of in vivo binding sites of chromatin proteins using tethered dam methyltransferase $[96,97]$ showed that the clustered Baril elements in the h39 region of the 2nd chromosome are targets of HP1, a chromatin protein mainly involved in heterochromatin formation [98]. It has been reported that Bari1 also contains Polycomb responsive elements that could collaborate in recruiting additional heterochromatin components [91]. This could be of particular relevance when clustered copies of Baril are exploited in the genome. It is therefore possible that both Bari1 clusters could have acquired a structural role in the heterochromatin of $D$. melanogaster, such as to ensure proper chromosome conformation and stability over the cell cycle.

\section{The Blurry Promoter: Who Wants to Live Forever?}

Along with the characterization of the Bari1 transposition system, the strength of the Bari1 promoter was tested. Luciferase promoter assays [99] conducted in fly cell cultures $\left(\mathrm{S} \mathrm{R}^{+}\right)$revealed that Bari1 has a weak promoter if compared to the strong constitutive copia promoter [100]. Weak promoters are typical of the Tc1/mariner transposons, which suffer from overproduction inhibition and therefore tend to limit the amount of transposase [101]. Unexpectedly, the Bari1 promoter drives the reporter transcription also in human, bacteria, and yeast cells [100]. This is quite counterintuitive, since evolutionarily distant genomes (e.g., animal and bacteria) have profoundly different modes of transcription and promoter organization [102]. Surprisingly, the promoter of Bari3 also showed a similar promiscuous 
activity (Figure 3). Due to this feature, the promoters were named "blurry", to highlight that they do not "sharply" activate the transcription in a single or few closely related species. These findings led to the hypothesis that the members of the Bari family can take advantage of this feature to engage successful HTT events. The ability of TEs promoter to sustain the transcription of associated genes upon HTT is recognized as one of the bottlenecks that restricts the success of HTT [103]. The presence of blurry promoters was also assessed in other Tc1- and mariner-like TEs. This observation is in agreement with the known predisposition of Tc1/mariner elements to be horizontally transferred $[50,104]$. It also suggests a common origin of this promoter type, and a possible common survival strategy for the elements belonging to the Tc1/mariner superfamily [105]. The discovery of the blurry promoters in the Bari family has also opened the possibility to implement them, together with many other TE-derived transcriptional control sequences, into expression modules in order to expand the repertoire of the existing expression vectors with a considerable improvement of their performances [4].

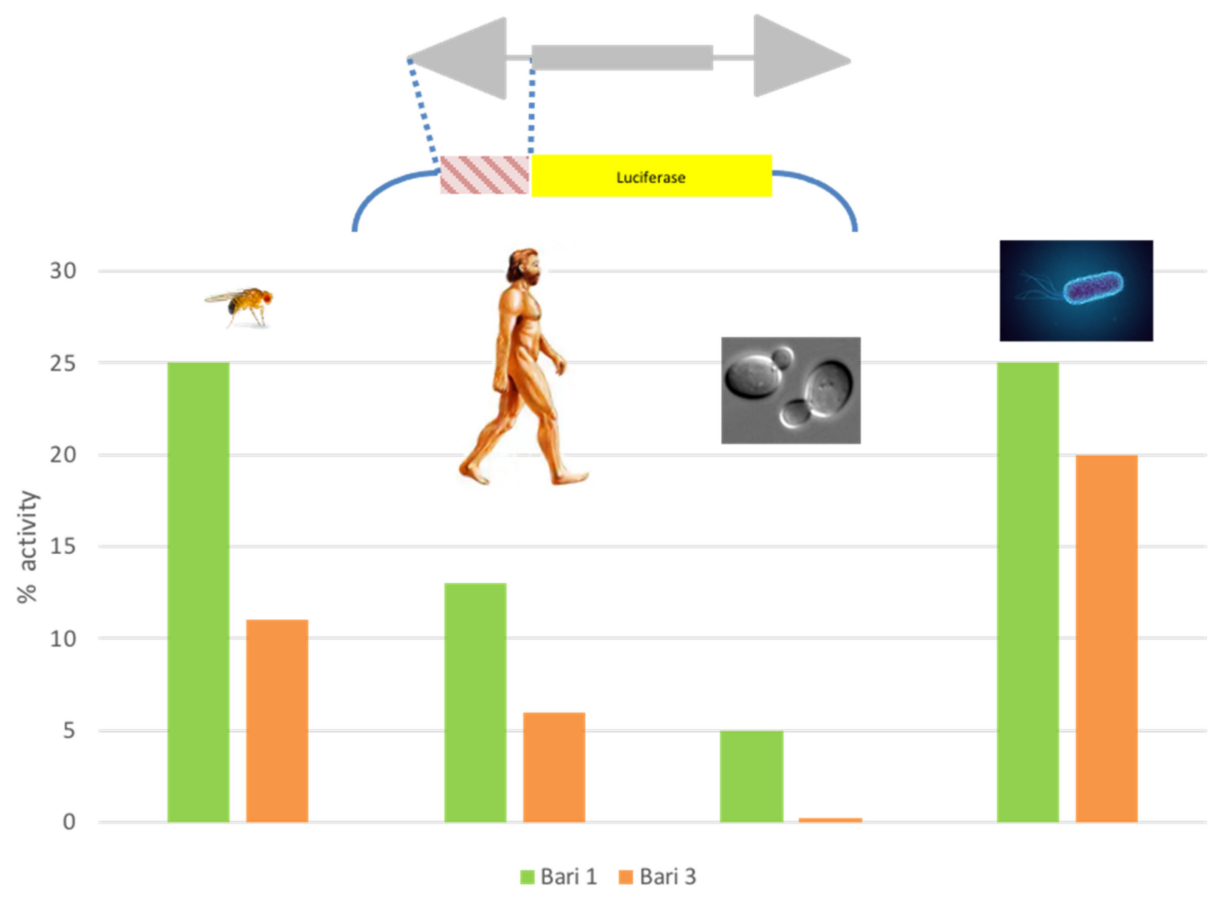

Figure 3. Activity of the native promoter of Bari1 and Bari3 in heterologous cellular systems. The transposon fragment tested in promoter-luciferase assays is depicted in the upper part of the figure. The $\%$ activity compared to strong species-specific constitutive promoters (SV40, copia, URA3, and CAT for human, fly, yeast, and bacteria cells, respectively), arbitrarily assumed as $100 \%$, is reported on $\mathrm{Y}$ axis of the chart.

\section{Concluding Remarks}

What We Have Learned and What We Still Have to Learn from Bari Transposons

In this review, we summarized the current scientific literature concerning the transposable elements belonging to the Bari family. Although the scientific interest around this transposon was mainly focused on its evolutionary history, several important experimental outcomes are worth noting, which have been (and hopefully will be in the future) important to deepen our understanding of TE biology.

Many aspects of the Bari transposons' biology are still not completely known and should be clarified, such as the low transposition rate in vitro. Studies on wild-collected fly populations will likely be the key to obtaining insights into the regulation of the Bari elements, as suggested by studies of Junakovic et al. [62].

It is possible that, as suggested by different studies, the Bari transposase could be intrinsically error-prone, and only occasionally it gives rise to productive transposition 
events. Fixing the transposase could possibly allow to obtain a robust transposition system. We still have to understand how the blurry promoter has evolved, and how it can be used to develop new tools for the genetic manipulation.

Finally, the determination of the structural and functional role of the heterochromatic clusters is a task that deserves further investigations, and will be accomplished with the aid of the genome editing technologies.

We think that more secrets associated to TEs remain to be discovered, and the continuous effort in dissecting the most diverse TEs in nature will contribute to clarifying the role of these genetic elements in evolution, hopefully attracting more interest in the field of TE biology, especially from emerging scientists.

Author Contributions: Writing—original draft preparation, A.P., R.C., R.M., and R.M.M.; writingreview and editing, A.P., R.C., R.M., and R.M.M. All authors have read and agreed to the published version of the manuscript.

Funding: A.P. is supported by a grant from Regione Puglia "Research for Innovation (REFIN)"-POR PUGLIA FESR-FSE 2014/2020. Codice Pratica: B39303C8.

Institutional Review Board Statement: Not applicable.

Informed Consent Statement: Not applicable.

Data Availability Statement: Not applicable.

Acknowledgments: We are grateful to Z. Ivics for constructive discussion and for supporting in vitro site-directed mutagenesis experiments in his lab. We are also grateful to all past members of the lab and all the graduating students for stimulating discussions.

Conflicts of Interest: The authors declare no conflict of interest.

\section{References}

1. Sandoval-Villegas, N.; Nurieva, W.; Amberger, M.; Ivics, Z. Contemporary Transposon Tools: A Review and Guide through Mechanisms and Applications of Sleeping Beauty, piggyBac and Tol2 for Genome Engineering. Int. J. Mol. Sci. 2021, $22,5084$. [CrossRef] [PubMed]

2. Li, X.; Burnight, E.R.; Cooney, A.L.; Malani, N.; Brady, T.; Sander, J.D.; Staber, J.; Wheelan, S.J.; Joung, J.K.; McCray, P.B., Jr.; et al. piggyBac transposase tools for genome engineering. Proc. Natl. Acad. Sci. USA 2013, 110, E2279-E2287. [CrossRef] [PubMed]

3. Kesselring, L.; Miskey, C.; Zuliani, C.; Querques, I.; Kapitonov, V.; Laukó, A.; Fehér, A.; Palazzo, A.; Diem, T.; Lustig, J.; et al. A single amino acid switch converts the Sleeping Beauty transposase into an efficient unidirectional excisionase with utility in stem cell reprogramming. Nucleic Acids Res. 2020, 48, 316-331. [CrossRef] [PubMed]

4. Palazzo, A.; Marsano, R.M. Transposable elements: A jump toward the future of expression vectors. Crit. Rev. Biotechnol. 2021, 41, 1-27. [CrossRef]

5. Rubin, G.M.; Spradling, A.C. Genetic transformation of Drosophila with transposable element vectors. Science 1982, 218, 348-353. [CrossRef]

6. Spradling, A.C.; Rubin, G.M. Transposition of cloned P elements into Drosophila germ line chromosomes. Science 1982, 218, 341-347. [CrossRef]

7. O'Brochta, D.A.; Handler, A.M. Mobility of P elements in drosophilids and nondrosophilids. Proc. Natl. Acad. Sci. USA 1988, 85, 6052-6056. [CrossRef]

8. Tenzen, T.; Matsutani, S.; Ohtsubo, E. Site-specific transposition of insertion sequence IS630. J. Bacteriol. 1990, 172, 3830-3836. [CrossRef]

9. Plasterk, R.H.A. The Tc1/mariner Transposon Family. In Transposable Elements; Saedler, H., Gierl, A., Eds.; Springer: Berlin/Heidelberg, Germany, 1996; pp. 125-143.

10. Miskey, C.; Izsvak, Z.; Kawakami, K.; Ivics, Z. DNA transposons in vertebrate functional genomics. Cell Mol. Life Sci. 2005, 62, 629-641. [CrossRef]

11. Prommersberger, S.; Reiser, M.; Beckmann, J.; Danhof, S.; Amberger, M.; Quade-Lyssy, P.; Einsele, H.; Hudecek, M.; Bonig, H.; Ivics, Z. CARAMBA: A first-in-human clinical trial with SLAMF7 CAR-T cells prepared by virus-free Sleeping Beauty gene transfer to treat multiple myeloma. Gene Ther. 2021, 28, 560-571. [CrossRef]

12. Wicker, T.; Gundlach, H.; Spannagl, M.; Uauy, C.; Borrill, P.; Ramírez-González, R.H.; De Oliveira, R.; Mayer, K.F.X.; Paux, E.; Choulet, F; et al. Impact of transposable elements on genome structure and evolution in bread wheat. Genome Biol. 2018, 19, 103. [CrossRef]

13. Bourque, G.; Burns, K.H.; Gehring, M.; Gorbunova, V.; Seluanov, A.; Hammell, M.; Imbeault, M.; Izsvák, Z.; Levin, H.L.; Macfarlan, T.S.; et al. Ten things you should know about transposable elements. Genome Biol. 2018, 19, 199. [CrossRef] 
14. Cain, A.K.; Barquist, L.; Goodman, A.L.; Paulsen, I.T.; Parkhill, J.; Van Opijnen, T. A decade of advances in transposon-insertion sequencing. Nat. Rev. Genet. 2020, 21, 526-540. [CrossRef]

15. Kaya-Okur, H.S.; Wu, S.J.; Codomo, C.A.; Pledger, E.S.; Bryson, T.D.; Henikoff, J.G.; Ahmad, K.; Henikoff, S. CUT\&Tag for efficient epigenomic profiling of small samples and single cells. Nat. Commun. 2019, 10, 1930. [CrossRef]

16. Caggese, C.; Caizzi, R.; Bozzetti, M.P.; Barsanti, P.; Ritossa, F. Genetic determinants of glutamine synthetase in Drosophila melanogaster: A gene for glutamine synthetase I resides in the 21B3-6 region. Biochem. Genet. 1988, 26, 571-584. [CrossRef]

17. Caggese, C.; Caizzi, R.; Barsanti, P.; Bozzetti, M.P. Mutations in the glutamine synthetase I (gsI) gene produce embryo-lethal female sterility in Drosophila melanogaster. Dev. Genet. 1992, 13, 359-366. [CrossRef]

18. Caizzi, R.; Bozzetti, M.P.; Caggese, C.; Ritossa, F. Homologous nuclear genes encode cytoplasmic and mitochondrial glutamine synthetase in Drosophila melanogaster. J. Mol. Biol. 1990, 212, 17-26. [CrossRef]

19. Pimpinelli, S.; Dimitri, P. Cytogenetic analysis of segregation distortion in Drosophila melanogaster: The cytological organization of the Responder (Rsp) locus. Genetics 1989, 121, 765-772. [CrossRef]

20. Wu, C.I.; True, J.R.; Johnson, N. Fitness reduction associated with the deletion of a satellite DNA array. Nature 1989, 341, 248-251. [CrossRef]

21. Wu, C.-I.; Lyttle, T.W.; Wu, M.-L.; Lin, G.-F. Association between a satellite DNA sequence and the responder of segregation distorter in D. melanogaster. Cell 1988, 54, 179-189. [CrossRef]

22. Brittnacher, J.G.; Ganetzky, B. On the components of segregation distortion in Drosophila melanogaster. IV. Construction and analysis of free duplications for the Responder locus. Genetics 1989, 121, 739-750. [CrossRef] [PubMed]

23. Ganetzky, B. On the components of segregation distortion in Drosophila melanogaster. Genetics 1977, 86, 321-355. [CrossRef] [PubMed]

24. Moschetti, R.; Chlamydas, S.; Marsano, R.M.; Caizzi, R. Conserved motifs and dynamic aspects of the terminal inverted repeat organization within Bari-like transposons. Mol. Genet. Genom. 2008, 279, 451-461. [CrossRef] [PubMed]

25. Plasterk, R.H.; Izsvák, Z.; Ivics, Z. Resident aliens: The Tc1/mariner superfamily of transposable elements. Trends Genet. 1999, 15, 326-332. [CrossRef]

26. Petrov, D.A.; Schutzman, J.L.; Hartl, D.L.; Lozovskaya, E.R. Diverse transposable elements are mobilized in hybrid dysgenesis in Drosophila virilis. Proc. Natl. Acad. Sci. USA 1995, 92, 8050-8054. [CrossRef]

27. Merriman, P.J.; Grimes, C.D.; Ambroziak, J.; Hackett, D.A.; Skinner, P.; Simmons, M.J. S elements: A family of Tc1-like transposons in the genome of Drosophila melanogaster. Genetics 1995, 141, 1425-1438. [CrossRef]

28. Arcà, B.; Savakis, C. Distribution of the Transposable Element Minos in the Genus Drosophila. Genetica 2000, 108, 263-267. [CrossRef]

29. Izsvak, Z.; Khare, D.; Behlke, J.; Heinemann, U.; Plasterk, R.H.; Ivics, Z. Involvement of a bifunctional, paired-like DNA-binding domain and a transpositional enhancer in Sleeping Beauty transposition. J. Biol. Chem. 2002, 277, 34581-34588. [CrossRef]

30. Palazzo, A.; Lovero, D.; D'Addabbo, P.; Caizzi, R.; Marsano, R.M. Identification of Bari Transposons in 23 Sequenced Drosophila Genomes Reveals Novel Structural Variants, MITEs and Horizontal Transfer. PLoS ONE 2016, 11, e0156014. [CrossRef]

31. McGurk, M.P.; Barbash, D.A. Double insertion of transposable elements provides a substrate for the evolution of satellite DNA Genome Res. 2018, 28, 714-725. [CrossRef]

32. Caizzi, R.; Caggese, C.; Pimpinelli, S. Bari-1, a new transposon-like family in Drosophila melanogaster with a unique heterochromatic organization. Genetics 1993, 133, 335-345. [CrossRef]

33. Caggese, C.; Pimpinelli, S.; Barsanti, P.; Caizzi, R. The distribution of the transposable element Bari-1 in the Drosophila melanogaster and Drosophila simulans genomes. Genetica 1995, 96, 269-283. [CrossRef]

34. Marsano, R.M.; Milano, R.; Minervini, C.; Moschetti, R.; Caggese, C.; Barsanti, P.; Caizzi, R. Organization and possible origin of the Bari-1 cluster in the heterochromatic h39 region of Drosophila melanogaster. Genetica 2003, 117, 281-289. [CrossRef]

35. Berloco, M.F.; Minervini, C.F.; Moschetti, R.; Palazzo, A.; Viggiano, L.; Marsano, R.M. Evidence of the Physical Interaction between Rpl22 and the Transposable Element Doc5, a Heterochromatic Transposon of Drosophila melanogaster. Genes 2021, 12, 1997. [CrossRef]

36. Marsano, R.M.; Marconi, S.; Moschetti, R.; Barsanti, P.; Caggese, C.; Caizzi, R. MAX, a novel retrotransposon of the BEL-Pao family, is nested within the Bari1 cluster at the heterochromatic h39 region of chromosome 2 in Drosophila melanogaster. Mol. Genet. Genom. 2004, 270, 477-484. [CrossRef]

37. Marsano, R.M.; Moschetti, R.; Barsanti, P.; Caggese, C.; Caizzi, R. A survey of the DNA sequences surrounding the Bari1 repeats in the pericentromeric $\mathrm{h} 39$ region of Drosophila melanogaster. Gene 2003, 307, 167-174. [CrossRef]

38. Crooks, G.E.; Hon, G.; Chandonia, J.M.; Brenner, S.E. WebLogo: A sequence logo generator. Genome Res. 2004, 14, 1188-1190. [CrossRef]

39. Moschetti, R.; Caggese, C.; Barsanti, P.; Caizzi, R. Intra- and interspecies variation among Bari-1 elements of the melanogaster species group. Genetics 1998, 150, 239-250. [CrossRef]

40. Hartl, D.L.; Lozovskaya, E.R.; Nurminsky, D.I.; Lohe, A.R. What restricts the activity of mariner-like transposable elements. Trends Genet. 1997, 13, 197-201. [CrossRef]

41. Claeys Bouuaert, C.; Chalmers, R.M. Gene therapy vectors: The prospects and potentials of the cut-and-paste transposons. Genetica 2010, 138, 473-484. [CrossRef]

42. Palazzo, A.; Moschetti, R.; Caizzi, R.; Marsano, R.M. The Drosophila mojavensis Bari3 transposon: Distribution and functional characterization. Mob. DNA 2014, 5, 21. [CrossRef] [PubMed] 
43. Bureau, T.E.; Wessler, S.R. Tourist: A large family of small inverted repeat elements frequently associated with maize genes. Plant Cell 1992, 4, 1283-1294. [CrossRef] [PubMed]

44. Jiang, N.; Feschotte, C.; Zhang, X.; Wessler, S.R. Using rice to understand the origin and amplification of miniature inverted repeat transposable elements (MITEs). Curr. Opin. Plant Biol. 2004, 7, 115-119. [CrossRef] [PubMed]

45. Quesneville, H.; Nouaud, D.; Anxolabéhère, D. P elements and MITE relatives in the whole genome sequence of Anopheles gambiae. BMC Genom. 2006, 7, 214. [CrossRef]

46. De Freitas Ortiz, M.; Silva Loreto, E.L. The hobo-related elements in the melanogaster species group. Genet. Res. 2008, 90, 243-252. [CrossRef]

47. Dias, E.S.; Carareto, C.M. msechBari, a new MITE-like element in Drosophila sechellia related to the Bari transposon. Genet. Res. 2011, 93, 381-385. [CrossRef]

48. Keeling, P.J. Functional and ecological impacts of horizontal gene transfer in eukaryotes. Curr. Opin. Genet. Dev. 2009, 19, 613-619. [CrossRef]

49. Boto, L. Horizontal gene transfer in the acquisition of novel traits by metazoans. Proc. Biol. Sci. 2014, 281, 20132450. [CrossRef]

50. Schaack, S.; Gilbert, C.; Feschotte, C. Promiscuous DNA: Horizontal transfer of transposable elements and why it matters for eukaryotic evolution. Trends Evol. 2010, 25, 537-546. [CrossRef]

51. Wallau, G.L.; Vieira, C.; Loreto, É.L.S. Genetic exchange in eukaryotes through horizontal transfer: Connected by the mobilome. Mob. DNA 2018, 9, 6. [CrossRef]

52. Wallau, G.L.; Capy, P.; Loreto, E.; Le Rouzic, A.; Hua-Van, A. VHICA, a New Method to Discriminate between Vertical and Horizontal Transposon Transfer: Application to the Mariner Family within Drosophila. Mol. Biol. Evol. 2016, 33, 1094-1109. [CrossRef]

53. Dias, E.S.; Carareto, C.M. Ancestral polymorphism and recent invasion of transposable elements in Drosophila species. BMC Evol. Biol. 2012, 12, 119. [CrossRef]

54. Bartolome, C.; Bello, X.; Maside, X. Widespread evidence for horizontal transfer of transposable elements across Drosophila genomes. Genome Biol. 2009, 10, R22. [CrossRef]

55. Ometto, L.; Cestaro, A.; Ramasamy, S.; Grassi, A.; Revadi, S.; Siozios, S.; Moretto, M.; Fontana, P.; Varotto, C.; Pisani, D.; et al. Linking genomics and ecology to investigate the complex evolution of an invasive Drosophila pest. Genome Biol. Evol. 2013, 5, 745-757. [CrossRef]

56. Moschetti, R.; Marsano, R.M.; Barsanti, P.; Caggese, C.; Caizzi, R. FB elements can promote exon shuffling: A promoterless white allele can be reactivated by FB mediated transposition in Drosophila melanogaster. Mol. Genet. Genom. 2004, 271, 394-401. [CrossRef]

57. Capy, P.; Gasperi, G.; Biémont, C.; Bazin, C. Stress and transposable elements: Co-evolution or useful parasites? Heredity 2000, 85, 101-106. [CrossRef]

58. Feng, G.; Leem, Y.-E.; Levin, H.L. Transposon integration enhances expression of stress response genes. Nucleic Acids Res. 2013 41, 775-789. [CrossRef]

59. Rech, G.E.; Bogaerts-Márquez, M.; Barrón, M.G.; Merenciano, M.; Villanueva-Cañas, J.L.; Horváth, V.; Fiston-Lavier, A.-S.; Luyten, I.; Venkataram, S.; Quesneville, H.; et al. Stress response, behavior, and development are shaped by transposable element-induced mutations in Drosophila. PLoS Genet. 2019, 15, e1007900. [CrossRef]

60. Horváth, V.; Merenciano, M.; González, J. Revisiting the Relationship between Transposable Elements and the Eukaryotic Stress Response. Trends Genet. 2017, 33, 832-841. [CrossRef]

61. Palazzo, A.; Marconi, S.; Specchia, V.; Bozzetti, M.P.; Ivics, Z.; Caizzi, R.; Marsano, R.M. Functional Characterization of the Bari1 Transposition System. PLoS ONE 2013, 8, e79385. [CrossRef]

62. Junakovic, N.; Di Franco, C.; Terrinoni, A. Evidence for a host role in regulating the activity of transposable elements in Drosophila melanogaster: The case of the persistent instability of Bari 1 elements in Charolles stock. Genetica 1997, 100, 149-154. [CrossRef] [PubMed]

63. Soriano, S.; Fortunati, D.; Junakovic, N. Evidence for the Host Contribution in the Definition of Preferential Insertion Sites of the Elements of Bari 1 Transposon Family in Drosophila melanogaster. J. Mol. Evol. 2002, 55, 606-615. [CrossRef] [PubMed]

64. Marsano, R.M.; Caizzi, R.; Moschetti, R.; Junakovic, N. Evidence for a functional interaction between the Bari1 transposable element and the cytochrome P450 cyp12a4 gene in Drosophila melanogaster. Gene 2005, 357, 122-128. [CrossRef]

65. Specchia, V.; Piacentini, L.; Tritto, P.; Fanti, L.; D’Alessandro, R.; Palumbo, G.; Pimpinelli, S.; Bozzetti, M.P. Hsp90 prevents phenotypic variation by suppressing the mutagenic activity of transposons. Nature 2010, 463, 662-665. [CrossRef] [PubMed]

66. Specchia, V.; Bozzetti, M.P. The Role of HSP90 in Preserving the Integrity of Genomes Against Transposons Is Evolutionarily Conserved. Cells 2021, 10, 1096. [CrossRef]

67. Pimpinelli, S.; Piacentini, L. Environmental change and the evolution of genomes: Transposable elements as translators of phenotypic plasticity into genotypic variability. Funct. Ecol. 2020, 34, 428-441. [CrossRef]

68. Malone, C.D.; Hannon, G.J. Small RNAs as guardians of the genome. Cell 2009, 136, 656-668. [CrossRef]

69. Brennecke, J.; Aravin, A.A.; Stark, A.; Dus, M.; Kellis, M.; Sachidanandam, R.; Hannon, G.J. Discrete small RNA-generating loci as master regulators of transposon activity in Drosophila. Cell 2007, 128, 1089-1103. [CrossRef]

70. Grewal, S.I.S.; Elgin, S.C.R. Transcription and RNA interference in the formation of heterochromatin. Nature 2007, 447, 399-406. [CrossRef] 
71. Wang, S.H.; Elgin, S.C.R. Drosophila Piwi functions downstream of piRNA production mediating a chromatin-based transposon silencing mechanism in female germ line. Proc. Natl. Acad. Sci. USA 2011, 108, 21164-21169. [CrossRef]

72. Le Thomas, A.; Rogers, A.K.; Webster, A.; Marinov, G.K.; Liao, S.E.; Perkins, E.M.; Hur, J.K.; Aravin, A.A.; Tóth, K.F. Piwi induces piRNA-guided transcriptional silencing and establishment of a repressive chromatin state. Genes Dev. 2013, 27, 390-399. [CrossRef]

73. Wang, H.; Ma, Z.; Niu, K.; Xiao, Y.; Wu, X.; Pan, C.; Zhao, Y.; Wang, K.; Zhang, Y.; Liu, N. Antagonistic roles of Nibbler and Hen1 in modulating piRNA $3^{\prime}$ ends in Drosophila. Development 2016, 143, 530-539. [CrossRef]

74. Pritykin, Y.; Brito, T.; Schupbach, T.; Singh, M.; Pane, A. Integrative analysis unveils new functions for the Drosophila Cutoff protein in noncoding RNA biogenesis and gene regulation. RNA 2017, 23, 1097-1109. [CrossRef]

75. Wang, J.; Zhang, P.; Lu, Y.; Li, Y.; Zheng, Y.; Kan, Y.; Chen, R.; He, S. piRBase: A comprehensive database of piRNA sequences. Nucleic Acids Res. 2019, 47, D175-D180. [CrossRef]

76. Chlamydas, S.; Heun, P.; Dimitri, P.; Moschetti, R.; Barsanti, P.; Caizzi, R. The paracentric inversion In(2Rh)PL alters the centromeric organization of chromosome 2 in Drosophila melanogaster. Chromosome Res. 2009, 17, 1-9. [CrossRef]

77. Zhang, F.; Wang, J.; Xu, J.; Zhang, Z.; Koppetsch, B.S.; Schultz, N.; Vreven, T.; Meignin, C.; Davis, I.; Zamore, P.D.; et al. UAP56 couples piRNA clusters to the perinuclear transposon silencing machinery. Cell 2012, 151, 871-884. [CrossRef]

78. Grentzinger, T.; Armenise, C.; Brun, C.; Mugat, B.; Serrano, V.; Pelisson, A.; Chambeyron, S. piRNA-mediated transgenerational inheritance of an acquired trait. Genome Res. 2012, 22, 1877-1888. [CrossRef]

79. Mugat, B.; Akkouche, A.; Serrano, V.; Armenise, C.; Li, B.; Brun, C.; Fulga, T.A.; Van Vactor, D.; Pélisson, A.; Chambeyron, S. MicroRNA-Dependent Transcriptional Silencing of Transposable Elements in Drosophila Follicle Cells. PLoS Genet. 2015, 11, e1005194. [CrossRef]

80. Olovnikov, I.; Ryazansky, S.; Shpiz, S.; Lavrov, S.; Abramov, Y.; Vaury, C.; Jensen, S.; Kalmykova, A. De novo piRNA cluster formation in the Drosophila germ line triggered by transgenes containing a transcribed transposon fragment. Nucleic Acids Res. 2013, 41, 5757-5768. [CrossRef]

81. Feltzin, V.L.; Khaladkar, M.; Abe, M.; Parisi, M.; Hendriks, G.J.; Kim, J.; Bonini, N.M. The exonuclease Nibbler regulates age-associated traits and modulates piRNA length in Drosophila. Aging Cell 2015, 14, 443-452. [CrossRef]

82. Chirn, G.W.; Rahman, R.; Sytnikova, Y.A.; Matts, J.A.; Zeng, M.; Gerlach, D.; Yu, M.; Berger, B.; Naramura, M.; Kile, B.T.; et al. Conserved piRNA Expression from a Distinct Set of piRNA Cluster Loci in Eutherian Mammals. PLoS Genet. 2015, 11, e1005652. [CrossRef] [PubMed]

83. Shpiz, S.; Ryazansky, S.; Olovnikov, I.; Abramov, Y.; Kalmykova, A. Euchromatic transposon insertions trigger production of novel Pi- and endo-siRNAs at the target sites in the drosophila germline. PLoS Genet. 2014, 10, e1004138. [CrossRef] [PubMed]

84. Loreto, E.L.S.; Pereira, C.M. Somatizing the transposons action. Mob. Genet. Elem. 2017, 7, 1-9. [CrossRef]

85. Perrat, P.N.; DasGupta, S.; Wang, J.; Theurkauf, W.; Weng, Z.; Rosbash, M.; Waddell, S. Transposition-driven genomic heterogeneity in the Drosophila brain. Science 2013, 340, 91-95. [CrossRef] [PubMed]

86. Treiber, C.D.; Waddell, S. Resolving the prevalence of somatic transposition in Drosophila. Elife 2017, 6, e28297. [CrossRef] [PubMed]

87. Treiber, C.D.; Waddell, S. Transposon expression in the Drosophila brain is driven by neighboring genes and diversifies the neural transcriptome. bioRxiv 2019, 838045. [CrossRef] [PubMed]

88. Siudeja, K.; Nassari, S.; Gervais, L.; Skorski, P.; Lameiras, S.; Stolfa, D.; Zande, M.; Bernard, V.; Frio, T.R.; Bardin, A.J. Frequent Somatic Mutation in Adult Intestinal Stem Cells Drives Neoplasia and Genetic Mosaicism during Aging. Cell Stem Cell 2015, 17, 663-674. [CrossRef] [PubMed]

89. Siudeja, K.; Van den Beek, M.; Riddiford, N.; Boumard, B.; Wurmser, A.; Stefanutti, M.; Lameiras, S.; Bardin, A.J. Unraveling the features of somatic transposition in the Drosophila intestine. Embo J. 2021, 40, e106388. [CrossRef]

90. Adams, M.D.; Celniker, S.E.; Holt, R.A.; Evans, C.A.; Gocayne, J.D.; Amanatides, P.G.; Scherer, S.E.; Li, P.W.; Hoskins, R.A.; Galle, R.F.; et al. The genome sequence of Drosophila melanogaster. Science 2000, 287, 2185-2195. [CrossRef]

91. Guio, L.; Barron, M.G.; Gonzalez, J. The transposable element Bari-Jheh mediates oxidative stress response in Drosophila. Mol. Ecol. 2014, 23, 2020-2030. [CrossRef]

92. Guio, L.; Vieira, C.; Gonzalez, J. Stress affects the epigenetic marks added by natural transposable element insertions in Drosophila melanogaster. Sci. Rep. 2018, 8, 12197. [CrossRef]

93. Slotkin, R.K.; Martienssen, R. Transposable elements and the epigenetic regulation of the genome. Nat. Rev. Genet. 2007, 8, 272-285. [CrossRef]

94. Caizzi, R.; Moschetti, R.; Piacentini, L.; Fanti, L.; Marsano, R.M.; Dimitri, P. Comparative Genomic Analyses Provide New Insights into the Evolutionary Dynamics of Heterochromatin in Drosophila. PLoS Genet. 2016, 12, e1006212. [CrossRef]

95. Moschetti, R.; Palazzo, A.; Lorusso, P.; Viggiano, L.; Marsano, R.M. “What You Need, Baby, I Got It": Transposable Elements as Suppliers of Cis-Operating Sequences in Drosophila. Biology 2020, 9, 25. [CrossRef]

96. Van Steensel, B.; Henikoff, S. Identification of in vivo DNA targets of chromatin proteins using tethered Dam methyltransferase. Nat. Biotechnol. 2000, 18, 424-428. [CrossRef]

97. Van Steensel, B.; Delrow, J.; Henikoff, S. Chromatin profiling using targeted DNA adenine methyltransferase. Nat. Genet. 2001, 27, 304-308. [CrossRef]

98. Casale, A.M.; Cappucci, U.; Piacentini, L. Unravelling HP1 functions: Post-transcriptional regulation of stem cell fate. Chromosoma 2021, 130, 103-111. [CrossRef] 
99. Brasier, A.R.; Ron, D. Luciferase reporter gene assay in mammalian cells. In Methods Enzymol; Academic Press: Cambridge, MA, USA, 1992; Volume 216, pp. 386-397.

100. Palazzo, A.; Caizzi, R.; Viggiano, L.; Marsano, R.M. Does the Promoter Constitute a Barrier in the Horizontal Transposon Transfer Process? Insight from Bari Transposons. Genome Biol. Evol. 2017, 9, 1637-1645. [CrossRef]

101. Hartl, D.L.; Lohe, A.R.; Lozovskaya, E.R. Regulation of the transposable element mariner. Genetica 1997, 100, 177-184. [CrossRef]

102. Kanhere, A.; Bansal, M. Structural properties of promoters: Similarities and differences between prokaryotes and eukaryotes. Nucleic Acids 2005, 33, 3165-3175. [CrossRef]

103. Silva, J.C.; Loreto, E.L.; Clark, J.B. Factors that affect the horizontal transfer of transposable elements. Curr. Issues Mol. Biol. 2004, 6, 57-71. [PubMed]

104. Peccoud, J.; Loiseau, V.; Cordaux, R.; Gilbert, C. Massive horizontal transfer of transposable elements in insects. Proc. Natl. Acad. Sci. USA 2017, 114, 4721-4726. [CrossRef] [PubMed]

105. Palazzo, A.; Lorusso, P.; Miskey, C.; Walisko, O.; Gerbino, A.; Marobbio, C.M.T.; Ivics, Z.; Marsano, R.M. Transcriptionally promiscuous "blurry" promoters in Tc1/mariner transposons allow transcription in distantly related genomes. Mob. DNA 2019, 10, 13. [CrossRef] [PubMed] 